\title{
GSM based electronic voting machine using touch screen
}

\author{
${ }^{1}$ Sreenath.M, ${ }^{2}$ Sukumar.P, ${ }^{3}$ Naganarasaiah Goud.K, ${ }^{4}$ P.Sivakalyani, \\ ${ }^{5}$ V. Phani Kumar, \\ ${ }^{1234}$ Asst. Professors, Dept.Of E.C.E., A.I.T.S., Rajampet, \\ ${ }^{5}$ Lecturer, Dept. of ECE., Govt.Polytechnic college,Obulavaripalli, Kadapa,A.P., India.
}

\begin{abstract}
The Electronic voting machine plays a key role in elections. The major drawbacks like it needs more man power, time and mislead the voting scenario due to influence of local people. The proposed system overcome the above problems using biometric (FINGERPRINT), Touch screen based GLCD and GSM modules. Finger print authentication is used to identify the voter and display the voter information on graphical LCD. If the person is authenticated then the vote is issued and the polling process is done using the touch screen, else that denies the process. At every regular intervals of time the polled votes are transferred to the server through GSM module. The GSM module receives the polled votes and updates the database. At the end of voting session the server counts all the polled votes and display on LED module. This system gives an efficient way to conduct elections and display the results on the same day.
\end{abstract}

Keywords: Biometric, Touch screen based GLCD, Microcontroller, GSM module.

\section{Introduction}

EMBEDDED Technology is now in its prime and the wealth of knowledge available is mind-blowing. Embedded technology plays a major role in integrating the various functions associated with it. This needs to tie up the various sources of the Department in a closed loop system. This proposal greatly reduces the manpower, saves time and operates efficiently without human interference. This project puts forth the first step in achieving the desired target. An embedded system is a combination of software and hardware to perform a dedicated task. Some of the main devices used in embedded products are Microprocessors and Microcontrollers. Microprocessors are commonly referred to as general purpose processors as they simply accept the inputs, process it and give the output. In contrast, a microcontroller not only accepts the data as inputs but also manipulates it, interfaces the data with various devices, controls the data and thus finally gives the result. Now a day's it is important to conduct elections without rigging. To develop such a system we are using biometric [1] application i.e. Finger Print Module [2] (NG-OP67) which consist of Blue Back Light Finger Print Sensor, high performance DSP \& Flash memory. The finger print image is captured by finger print sensor and stored in Flash memory in digital form. Finger print authentication for identifying the person and data is displayed on graphical LCD and polling process is done by touch screen. The finger print access control project will pull up information from data base and cross check it with the finger print and then grants access or denies it. The finger print access with database then screen display details of voter information and political parties. By touching the symbol of party which we want to vote the vote will be polled. By using this we can reduce the rigging of votes, man power and election cost. This NG-OP67 is interfaced with microcontroller through MAX232. We use ATMEGA32 (32k of flash programmable memory) for this purpose. We used Graphical LCD to display commands, this GLCD is also interfaced with ATMEGA32 at port C[4]. Touch screen can be used only for vote polling purpose. It is interfaced with the microcontroller (ATMEGA32) of port A ADC pins. Touch screen is placed above Graphical LCD[3]. By giving input at finger print module ie., by placing finger on finger print module it compares it with previously stored data and if it matches it allows the person to vote. We used Buzzer Indicator for vote conformation.

\section{System Architecture}

The main aim of the system is to establish a medium between airhostess and passengers. We are going to place this mechanism in the back side seat of a passenger in the plane. So this can easily visible to the next passengers to operate. We are displaying the graphics on the GLCD[3] according to the passenger requirement, which are already coded into the micro controller. A touch screen in placed on the top of the GLCD.If the passenger wants to order anything, by pressing a gentile touch on that the touch screen[5] the concerned co-ordinates will be sent to the micro controller. The working of project is as follows: After switch on the power supply, graphical LCD displays the project name after some time delay it displays three options.

1. Read: It is for reading the image entered through the finger print module and to poll vote for specified party.

2. Store: It is for entering the data base of the voters to voter list for polling purpose. 
3. Result: It is for to see the final result after election that now many votes each party has got.

By touching the read operation it displays "place your finger" after placing finger on finger print module it reads our data \& compares it with previously stored data, if it matches it displays the voter details \& after that it displays the party symbols on the screen, by touching any party symbol we want the vote will be polled, after the vote is polled the buzzer will indicated.

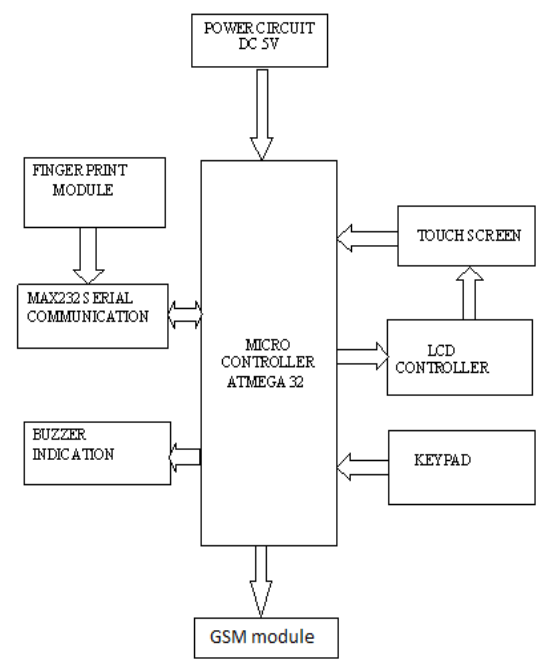

Fig 1: Block Diagram of GSM based EVMT

\section{Microcontroller(Atmega32)}

The ATmega32 is a low-power CMOS 8-bit microcontroller based on the AVR enhanced RISC architecture. By executing powerful instructions in a single clock cycle, the ATmega32[6] achieves throughputs approaching 1 MIPS per MHz allowing the system designer to optimize power consumption versus processing speed.

The AVR core combines a rich instruction set with 32 general purpose working registers. All the 32 registers are directly connected to the Arithmetic Logic Unit (ALU), allowing two independent registers to be accessed in one single instruction executed in one clock cycle. The resulting architecture is more code efficient while achieving throughputs up to ten times faster than conventional CISC microcontrollers.

The ATmega32 provides the following features: $32 \mathrm{~K}$ bytes of In-System Programmable Flash Program memory with Read-While-Write capabilities, 1024 bytes EEPROM, 2K byte SRAM, 32 general purpose I/O lines, 32 general purpose working registers, a JTAG interface for Boundary-scan, On-chip Debugging support and programming, three flexible Timer/Counters with compare modes, Internal and External Interrupts, a serial programmable USART, a byte oriented Two-wire Serial Interface, an 8-channel, 10-bit ADC with optional differential input stage with programmable gain (TQFP package only), a programmable Watchdog Timer with Internal Oscillator, an SPI serial port, and six software selectable power saving modes. The Idle mode stops the CPU while allowing the USART, Two-wire interface, A/D Converter, SRAM, Timer/Counters, SPI port, and interrupt system to continue functioning. The Power-down mode saves the register contents but freezes the Oscillator, disabling all other chip functions until the next External Interrupt or Hardware Reset. In Power-save mode, the Asynchronous Timer continues to run, allowing the user to maintain a timer base while the rest of the device is sleeping.

The ADC Noise Reduction mode stops the CPU and all I/O modules except Asynchronous Timer and ADC, to minimize switching noise during ADC conversions. In Standby mode, the crystal/resonator Oscillator is running while the rest of the device is sleeping. This allows very fast start-up combined with low-power consumption. In Extended Standby mode, both the main Oscillator and the Asynchronous Timer continue to run. The device is manufactured using Atmel's high density nonvolatile memory technology. The On-chip ISP Flash allows the program memory to be reprogrammed in-system through an SPI serial interface, by a conventional nonvolatile memory programmer, or by an On-chip Boot program running on the AVR core. The boot program can use any interface to download the application program in the Application Flash memory. Software in the Boot Flash section will continue to run while the Application Flash section is updated, providing true Read-While-Write operation. By combining an 8-bit RISC CPU with In-System Self-Programmable Flash on a monolithic chip, the Atmel ATmega32 is a powerful microcontroller that provides a highly-flexible and cost-effective solution to many embedded control applications. 


\subsection{Introduction}

\section{Finger Print Module}

FIM01 (Fingerprint Identification Module) [7] is an evolutionary standalone fingerprint recognition module consisted of optic sensor and processing board. Its voltage is so low $(3.3 \mathrm{~V})$ enough to implement a series of 23,000 authentication consuming 4 piece of AA batteries and executes average 1.2 seconds of high speed authentication. As CPU and highly upgraded algorithm are embedded into a module, it provides high recognition ratio even to small-size, wet, dry, calloused fingerprint. Due to technologies of simple and robust hardware design and including keypad function of the existed DK in one board, it can be executed to develop viable applications and perform user enrollment and authentication needed for fingerprint recognition without a connection to PC.

\subsection{NG OP-67 Fingerprint}

NG OP-67 Blue backlight Fingerprint Sensor Module adopts the optic fingerprint sensor, which consists of high-performance DSP and Flash. NG OP-67 is able to conduct fingerprint image processing, template generation, template matching, fingerprint searching, template storage, etc.

\section{Concepts in Fingerprint System:}

Fingerprint algorithmic means capturing features from fingerprint image, it represents the fingerprint information. The saving, matching and capturing of fingerprint templates are all manipulated through fingerprint features.

- $1: 1$

Comparing 2 fingerprint templates, return info: matching or not matching.

- 1: N Searching

Search the matching fingerprint from numbers of fingerprint features. Return info: No matching features or having matching features and returning the matching feature's ID simultaneity. Default baud rate $9600 \mathrm{bps}$, could change to other standard baud rate, refer to the parameter in this document Outer Interface Standard

System parameter and interface:

Table 1: System Parameter And Interface

\begin{tabular}{|c|c|c|l|}
\hline serial number & Index & Parameter & Condition \\
\hline 1 & Power supply & $5 \mathrm{~V}$ & \\
\hline 2 & Working current & $170 \mathrm{~mA}$ & \\
\hline 3 & Peak value current & $200 \mathrm{~mA}$ & \\
\hline 4 & Fingerprint input time & $<250 \mathrm{~ms}$ & \\
\hline 5 & $1: 1$ matching time & $<600 \mathrm{~ms}$ & Matching features + matching fingerprint \\
\hline 6 & $1: 900$ searching time & $<2 \mathrm{~s}$ & \\
\hline 7 & Fingerprint capacity & Max. 960 & \\
\hline 8 & $\begin{array}{c}\text { FAR(False } \\
\text { Acceptance Rate) }\end{array}$ & $<0.001 \%$ & \\
\hline 9 & $\begin{array}{c}\text { FRR } \\
\text { (False Rejection Rate) }\end{array}$ & $<1.5 \%$ & \\
\hline 10 & $\begin{array}{c}\text { Fingerprint template } \\
\text { size }\end{array}$ & 512 bytes & \\
\hline 11 & Outer interface & UART & \\
\hline
\end{tabular}

Resistive Touch screen Technology:

\section{Touch Screen}

Resistive LCD touch screen monitors rely on a touch overlay, which is composed of a flexible top layer and a rigid bottom layer separated by insulating dots, attached to a touch screen controller[8]. The inside surface of each of the two layers is coated with a transparent metal oxide coating (ITO) that facilitates a gradient across each layer when voltage is applied. Pressing the flexible top sheet creates electrical contact between the resistive layers, producing a switch closing in the circuit. The control electronics alternate voltage between the layers and pass the resulting $\mathrm{X}$ and $\mathrm{Y}$ touch coordinates to the touch screen controller. The touch screen controller data is then passed on to the computer operating system for processing. Resistive touch screens [9] are composed of two flexible sheets coated with a resistive material and separated by an air gap or microdots. When contact is made to the surface of the touch screen, the two sheets are pressed together, registering the precise location of the touch. Because the touch screen senses input from 
contact with nearly any object (finger, stylus/pen, palm) resistive touch screens are a type of "passive"technology. A four-wire resistive touch screen panel consists of two flexible layers uniformly coated with a transparent resistive material and separated by an air gap. Electrodes placed along the edges of the layers provide a means for exciting and monitoring the touch screen.

\section{Code vision AVR:}

\section{Software}

Code Vision AVR is a C cross-compiler, Integrated development Environment and Automatic Program Generator designed for the Atmel AVR family of microcontrollers. The program is a native 3bit application that runs under the windows 95,98,NT4,2000 and XP operating systems. The C cross-complier implements nearly all the elements of the ANSI C language, as allowed by the AVR architecture, with some features added to take advantage of specificity of the AVR architecture and the embedded system needs. The compiled COFF object fields can be $\mathrm{C}$ source level debugged, with variable watching, using the Atmel AVR Studio debugger. Code vision AVR also contains the CodeWizardAVR Automatic program generator.

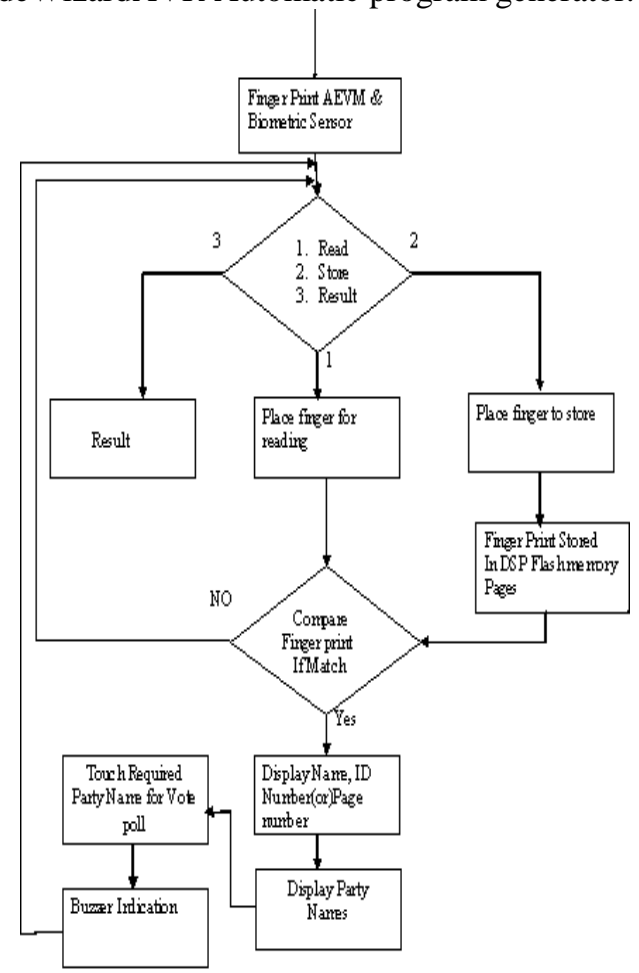

Fig 2: Flow Chart

\section{Results}

GSM based electronic voting machine using Touch Screen (EVMT) is shown below figure. Switch on the power supply. Graphical LCD displays the project name shown Fig 4. after some time delay it displays three options, Read, Store, Result.If read operation select it compares with previously stored data, if it matches it displays the voter details and after that it displays party symbols on the screen shown in Fig 6. on screen the vote will be polled according to the voter input by touching any party symbol, after the vote is polled the result stored in microcontroller.

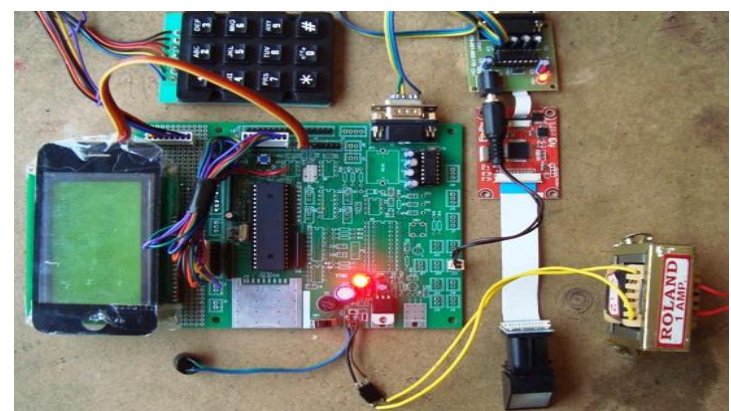

Fig3: Finger print IB Based AEVM with Touch Screen Polling 


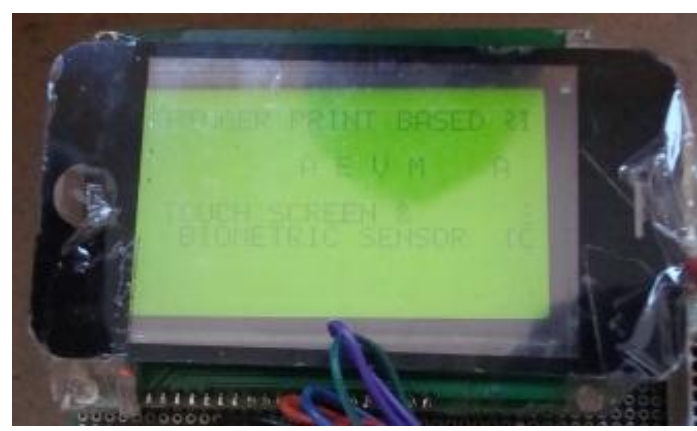

Fig 4: Project Name Display

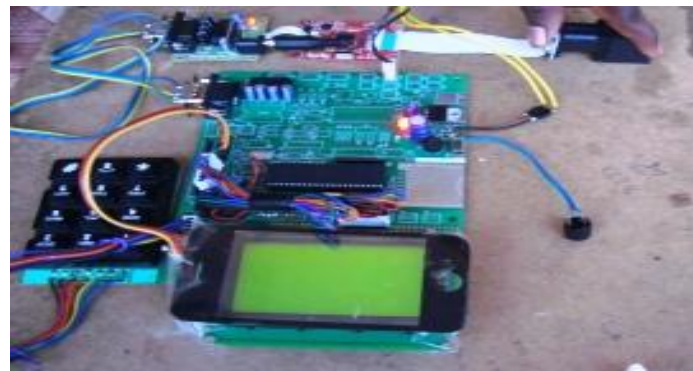

Fig 5: Finger Print Read Operation

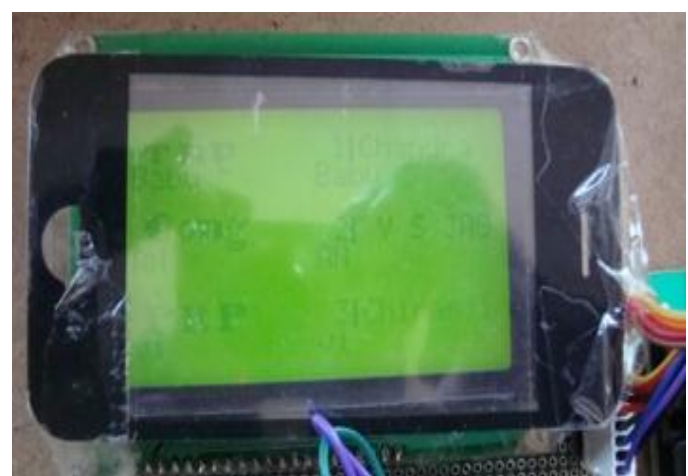

Fig 6: Political Party Names Display

\section{Conclusion}

This project is developed to overcome disadvantages of existing electronic voting machine. By using Finger Print Module there is no chance of rigging. Election cost, requirement of more man power and time are reduced. It can also to be used for security purpose .i.e Banks, offices, institutes.

\section{Future Scope}

By using high power Zigbee[10] module we can extend this range up to $1.3 \mathrm{~km}$. using Zigbee we can send text only. By using IR/RF transmitter and receiver we can send audio and video signals also. Touch screen used here is 4 wire resistive touch screen. Response time is also very less. By using other technology like surface technologies but it accepts only one touch at a acoustic wave or infrared we can further improve project so that it can accept more than touch at a time. By using internet module in addition to GSM based electronic voting machine using Touch Screen (EVMT) we can access votes from other regions. Here replicated data stored in main server automatically while polling of votes in sub regions

\section{References}

[1]. S. Prabhakar, S. Pankanti, and A. K. Jain, "Biometric Recognition: Security and Privacy Concerns", IEEE Security and Privacy Magazine, Vol. 1, No. 2, pp. 33-42, 2003.

[2]. L.Hong and A.K. Jain, "Integrating Faces and Fingerprints for Personal Identification", IEEE Trans. On Pattern Analysis and Machine Intelligence, Vol. 20. No. 12. PP. 1259-1307. Dec 1998.

[3]. "Atmel s Self-Programming Flash Microcontrollers" by Odd Jostein Svendsli 2003,Heilmeier, George; Castellano, Joseph; Zanoni, Louis (1969). "Guest-Host Interactions in Nematic Liquid Crystals". Molecular Crystals and Liquid Crystals 8: 293. doi:10.1080/15421406908084910.

[4]. A Preview on Microcontroller Based Electronic Voting Machine in Journal Of Information and Electronics Engineering ,Vol. 3, No. 2, March 2013. By diponkar Paul and Sobuj Kumar Ray, Member, IACSIT. 
[5]. Holzinger, A. (2003). " Finger Instead Of Mouse : Touch Screens as a means of enchancing Universal Access “. In: Carbonell, N.; Stephanidis. C.(Eds): Universal Access, Lecture Notes in Computer Science 2615.

[6]. Microcontroller Based Single Phase Digital Prepaid Energy Meter for Improved Metering and Billing System by $\quad$ Md. Mejbaul Haque, Md. Kamal Hossain, Md. Mortuza Ali, Md. Rafiqul Islam Sheikh. International Journal of Power Electronics and Drive System (IJPEDS) Vol.1, No.2, December 2011, pp. 139 147 ISSN: 2088-8694

[7]. D.Balzarotti, G. Banks, M. Cova, V. Felmetsger, R.A. Kemmerer,W. Robertson, F. Valeur, and G. Vigna, “ An Experience in Testing the security of Real-World Electronic Voting Systems “, IEEE Transactions on Software Engineering, Vol. 36, no. 4, 2010.

[8]. Hsu, Andrew. "Choosing a touch technology for handheld-system applications." EDN, January 8, 2009: 40-44.

[9]. Mudit Ratna Bhalla, Anand Vardhan Bhalla , "Comparative Study Of Various Touchscreen Technologies", International Journal of Computer Applications (0975-8887), Volume 6- No.8, September 2010.

[10]. Rudiger Schollmeier, A Definition of Peer-to-Peer Networking for the Classification of Peer-to-Peer Architectures and Applications, Proceedings of the First International Conference on Peer-to-Peer Computing, IEEE (2002).

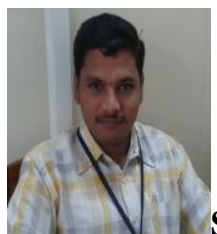

Sreenath.M, received B.Tech degree in ICE from JNTU Hyderabad and M.Tech degree in Embedded Systems from JNTU Anantapur. Currently working as Assistant Professor in the Department of E.C.E., Annamacharya Institute of Technology and Sciences, Rajampet, Kadapa, AndhraPradesh, India. Areas of interests are embedded Real Time systems, Microprocessors \& Microcontrollers and Control Systems.

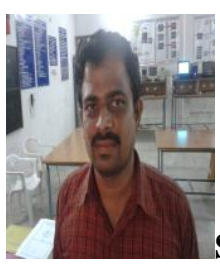

Sukumar.P, received B.Tech degree from JNTU Hyderabad and M.Tech degree from ANU Guntur. Currently working as Assistant Professor in the Department of E.C.E., Annamacharya Institute of Technology and Sciences, Rajampet, Kadapa, Andhra Pradesh, India. Area of interests are, Microprocessors \& Interfacing, embedded systems and Real Time Operating System.

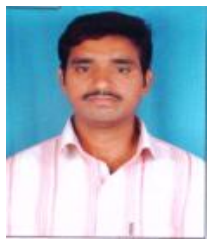

V.Phani Kumar received M.Tech (Digital Electronics and Communication) from J.N.T.U, Anantapur, AndhraPradesh, India. Completed B.Tech from Sri Venkateswara University College of Engineering, Tirupati, A.P, four years of experience in teaching and industry. Interested fields are Digital Image Processing, Wire less Communication Engineering and Digital Electronics. Present working as a Lecturer in the Dept of ECE at Govt.Polytechnic college,Obulavaripalli, Kadapa, A.P, India.

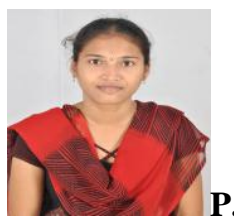

P.Sivakalyani, received B.Tech degree in ICE from JNTU Hyderabad and M.Tech degree in Embedded Systems from JNTU Anantapur. Currently working as Assistant Professor in the Department of E.C.E., Annamacharya Institute of Technology and Sciences, Rajampet, Kadapa, AndhraPradesh, India. Areas of interests are embedded systems, Microprocessors \& Microcontrollers and Pulse \& digital circuits.

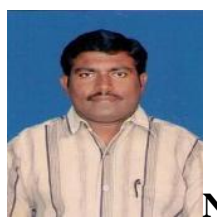

Naganarasaiah Goud.K, received B.Tech degree in ECE from JNTU Hyderabad and M.Tech degree in Embedded Systems from JNTU Hyderabad. Currently working as Assistant Professor in the Department of E.C.E., Annamachrya Institute of Technology and Sciences, Rajampet, Kadapa, Andhra Pradesh, India. Area of interests are embedded systems and Microprocessors \& Microcontrollers. 